Southern Illinois University Edwardsville SPARK

SIUE Faculty Research, Scholarship, and Creative Activity

7-8-2015

\title{
Strategic Similarity and Acquisition Outcomes at the Target: Evidence from China's Beer Industry
}

Yuping Zeng

Southern Illinois University Edwardsville, yzeng@siue.edu

Timothy Schoenecker

tschoen@siue.edu

Follow this and additional works at: http://spark.siue.edu/siue_fac

Part of the Strategic Management Policy Commons

\section{Recommended Citation}

Zeng, Y. P. and Schoenecker, T. S. Strategic Similarity and Target Performance in Horizontal Acquisitions: Evidence from China's Beer Industry. Asian Business and Management, July 8, 2015.

This Article is brought to you for free and open access by SPARK. It has been accepted for inclusion in SIUE Faculty Research, Scholarship, and Creative Activity by an authorized administrator of SPARK. For more information, please contact gpark@siue.edu. 


\section{Cover Page Footnote}

This is a post-peer-review, pre-copyedit version of an article published in Asian Business and Management. The definitive publisher-authenticated version "Zeng, Y., \& Schoenecker, T. S. (2015). Strategic similarity and acquisition outcomes at the target: Evidence from China's beer industry. Asian Business \& Management." is available online at: http://dx.doi.org/10.1057/abm.2015.9 


\title{
Strategic Similarity and Acquisition Outcomes at the Target: \\ Evidence from China's Beer Industry
}

\section{Yuping Zeng and Timothy S. Schoenecker}

\begin{abstract}
:
This study investigates the effect of horizontal acquisitions on target firms in China's context. We examine how competitive and organizational similarity jointly affect cost savings, revenue growth and profitability improvement at the target in horizontal acquisitions. Using a dataset containing information on acquired firms in China's beer industry, we find that the way in which competitive similarity impacts on cost savings at the target depends on organizational similarity and the type of cost that is examined. Additionally, competitive dissimilarity is found to result in higher revenue growth and profitability improvement at the target.
\end{abstract}

Key words: horizontal acquisition; strategic similarity; target outcomes; China 


\section{Introduction}

Horizontal acquisitions (HAs) continue to be a common strategic action taken by firms to grow and expand (Chen and Young, 2010; UNCTAD, 2012). However, despite their popularity, HAs do not always lead to positive outcomes - previous studies have reported a failure rate among HAs as high as 50 per cent (e.g. Papadakis and Thanos, 2010; Schoenberg, 2006). The high failure rate of HAs (and other types of acquisitions) has triggered a significant amount of research examining the determinants of acquisition outcomes (for reviews, see Cartwright and Schoenberg, 2006; Haleblian et al., 2009). The extant research, however, has predominantly focused on acquisitions conducted by firms in developed countries, leaving acquisitions in transition economies such as China under-examined. This study fills this research gap by examining HAs occurring in China's context. Furthermore, prior studies have focused primarily on outcomes at the acquirer or combined firm, whereas the effects of the HA on the target's post-acquisition operations remain under-investigated. This study addresses this need by examining cost savings, revenue growth, and profitability specifically at the acquired firm.

Similar to the experience of other countries transitioning from a centrally-planned to a market-oriented economic system, acquisitions in China usually occur against a background of government efforts to privatize or restructure state- or collectively- owned firms (Sheng, 1999; Xu et al., 2010; Zeng et al., 2013). Because most firms in transition economies are not freely tradable, the seller often plays a determinant role in the occurrence of acquisitions in these economies (Zeng et al., 2013). In particular, since some key stakeholders (e.g. supervising government, labor unions, and in some cases, managers) will continue to be affected by the target's operations post-acquisition, their selling decision (e.g. to whom to sell and under what conditions) is often driven by the target's long-term prospects rather than receiving the highest selling price (Antal-Mokos and Toth, 2007; 
Darskuviene, 2007; Meyer, 2002; Sheng, 1999; Uhlenbruck and De Castro, 1998). Furthermore, the target's stakeholders may also impact on its post-acquisition operations. For example, due to concerns over employment and local economic development, the local government may restrict layoffs at the target and encourage the acquirer to make further investments into the target, using mechanisms such as government loans and tax breaks (Sheng, 1999; Uhlenbruck and De Castro, 2000).

Given the important roles played by the target's stakeholders and their interests in the target's long-term prospects in China and other transitional economies, it is meaningful to understand factors impacting on the target's post-acquisition performance. In particular, for managers of the acquiring firm, such an understanding may be beneficial in two ways. First, these managers may be able to make proposals that are attractive to suitable targets, based in part on the likelihood of a more promising future for their business. Secondly, they may be able to better interact with key stakeholders of the target during the integration process, which consequently can lead to better acquisition performance.

Nevertheless, extant studies have focused primarily on the performance of the acquirer, and little is known about how the target performs after the acquisition, in particular in the case of HAs. ${ }^{1}$ This study overcomes this shortcoming by examining HA outcomes at the acquired firm. We focus on the effect of strategic similarity, a factor acknowledged as the most likely predictor of HA outcomes (Altunbas and Marques, 2008; Capron et al., 1998; Swaminathan et al., 2008).

Generally speaking, strategic similarity refers to similarities and differences in the combining firms' competitive activities as well as organizational features such as management style and structure. It has been posited that strategic similarity increases the potential for cost-saving synergies (Capron, 1999; Shelton, 1988) and facilitates the integration process (Datta, 1991; Ramaswamy, 
1997; Swaminathan et al., 2008). Meanwhile, it has also been argued that strategic differences increase the likelihood of achieving revenue-enhancing synergies by combining the two firms' resources (Barney, 1988; Harrison et al., 1991; Larsson and Finkelstein, 1999). Taking these two lines of thought into consideration, we examine both cost savings and revenue growth, in addition to profitability improvement, at the target. Additionally, we distinguish the two components of strategic similarity, namely competitive similarity and organizational similarity, and examine their interaction effect.

Typically, an acquired firm's post-acquisition operations cannot be studied with precision, because the financial results of the acquired firm are usually folded into the financial results of the combined entity. However, we are able to continue to track the financial performance of acquired firms due to a unique dataset maintained by the Chinese government that requires financial data to be reported at the plant level.

Our results show that cost savings, revenue growth, and profitability improvement at the target are all negatively related to competitive similarity. Additionally, we find that cost savings at the target are greatest when both competitive and organizational dissimilarity are high. This finding may reflect the realities that acquired firms in China are usually state-owned or former state-owned firms that need significant restructuring and that strategic dissimilarity provides more opportunities for effective changes to take place.

Our study contributes to our understanding of Asian business by examining how an HA target in China may be impacted by the level of strategic similarity between the acquirer and the target firm. Our results show that due to China's background of economic transition, targets acquired by competitively and organizationally different acquirers are likely to perform better than those acquired by more similar acquirers. 


\section{Theoretical background}

Strategic similarity and HA outcomes

HAs may benefit combining firms by leading to cost-saving synergies, revenue-enhancing synergies, or both (Barney, 2002; Capron, 1999; Capron et al., 1998; Walter and Barney, 1990). Cost savings may be the result of economies of scale and scope in various corporate and business-level activities or/and increased bargaining power over suppliers (Eckbo, 1983; Fee and Thomas, 2004; Teece, 1982). Growth in revenues may occur as a result of competency-enhancing synergies that lead to a stronger differentiated position. In turn, this may lead to increased prices or/and higher sales volume (Ahuja and Katila, 2001; Capron, 1999; Dranove and Shanley, 1995; Harrison et al., 1991; Saxton and Dollinger, 2004).

The potential magnitude of the combination synergies and the likelihood that they will be captured through an effective integration process are both affected by the degree to which the acquirer and target are strategically similar (Harrison et al., 1991; Kusewitt, 1985). While strategic similarity has multiple dimensions, it can be thought of as having two components: competitive similarity and organizational similarity (Jemison and Sitkin, 1986). Competitive similarity refers to the degree to which the two firms' operational and competing activities are alike. It determines the potential value that can be created from combining two firms and the level of integration needed to realize this potential (Homburg and Bucerius, 2006; Jemison and Sitkin, 1986; Larsson and Finkelstein, 1999). Organizational similarity refers to the degree to which two firms' organizational and cultural practices are alike and influences the effectiveness of the integration process (Chatterjee et al., 1992; Datta, 1991; Jemison and Sitkin, 1986). 
It has been agreed that organizational similarity positively affects acquisition outcomes by facilitating post-acquisition integration (Jemison and Sitkin, 1986). Empirical studies have generally supported this assertion (Chatterjee, 1986; Datta, 1991; Homburg and Bucerius, 2006). In contrast, divergent views exist regarding the outcomes of combining competitively similar and dissimilar firms.

On the one hand, traditional cost-efficiency theories suggest that competitive similarity between combining firms provides more opportunities to exploit economies of scale and scope, and therefore create more potential for cost-saving synergies (Chatterjee, 1986; Prahalad and Bettis, 1986; Ramaswamy, 1997). On the other hand, several scholars, drawing on the resource-based view of the firm, argue that the combination of firms with different resource configurations is more likely to result in private, unique and inimitable synergies, and therefore can lead to improved performance at the combining firms (Barney, 1988; Harrison et al., 1991). It has also been suggested that combining firms with different but complementary resources provides more opportunities to exploit revenue-enhancing synergies through product innovation and market extension (Hitt et al., 1998; Larsson and Finkelstein, 1999).

These divergent perspectives indicate that the effect that competitive similarity has on the combining firms depends on whether cost savings or revenue growth is examined. Specifically, while combining competitively similar firms is likely to lead to more cost savings, the combination of competitive dissimilar firms will likely result in more revenue growth. Against this theoretical background, we examine both cost savings and revenue enhancement at the target. ${ }^{2}$

In addition to affecting acquisition outcomes independently, organizational and competitive similarity may interact with each other as well. Stahl and Voigt (2008) examined the moderating effect that competitive similarity has on the relationship between organizational similarity and 
acquisition outcomes. They found that organizational differences are positively related to acquisition performance when competitive similarity is low, but negatively related to performance when competitive similarity is high. Complementing this study, we examine whether the effect that competitive similarity has on cost savings and revenue growth at the target depends on the level of organizational similarity.

\section{Acquisition outcome at the target: a seller's vs. a buyer's perspective}

Despite the intense investigation on acquisition outcomes, few studies have examined targets post-acquisition. Among the few that have, the majority focus on the negative impacts of the acquisition (e.g. management departure, employee resistance) (Cannella and Hambrick, 1993; Hambrick and Cannella, 1993; Larsson and Finkelstein, 1999; Walsh and Ellwood, 1991). This reflects the dominance of a buyer's perspective of acquisition, where buyers are viewed as the dominant player and sellers are portrayed as price-driven, reactive and reluctant (Graebner and Eisenhardt, 2004).

However, evidence shows that the emphasis on the buyer's perspective may not always be appropriate, particularly when the target is privately- or state-owned. In their studies of acquisitions involving private technology firms, Graebner and Eisenhardt (2004) found that the seller plays an active role in the acquisition process by selecting desirable buyers that offer long-term strategic fit and organizational rapport. Similar phenomena were found in acquisitions in Eastern European countries (EECs) (Antal-Mokos and Toth, 2007; Darskuviene, 2007). Zeng et al (2013) highlighted the determinant role played by sellers in acquisitions in China due to the fact that firms are either stated owned or not publically traded. Finally, Graebner (2004) found that leaders of the acquired firm play critical roles in synergy realization post-acquisition. 
These empirical findings have provoked scholars to appeal for the development of a seller's perspective on acquisition (Graebner and Eisenhardt, 2004; Zeng et al., 2013). Our focus on the target in the context of a transitional economy (e.g. China) allows us to advance this effort and incorporate the seller's perspective when examining acquisition outcomes. Specifically, when a seller plays an active role in selecting desirable buyers, the managers and other key stakeholders (e.g. local government in China) may be well aware of the sources of potential synergies and likely integration initiatives post-acquisition. They may also negotiate for integration initiatives that are beneficial to the target in the long run as a condition of sale. For example, it has been shown that in acquisitions in EECs, sellers may require buyers to make certain post-acquisition investments in the target (Uhlenbruck and De Castro, 1998, 2000). Additionally, it is likely that stakeholders affected by the long-term prospects of the target may work supportively with the acquirer after the acquisition to achieve the potential synergies. The above arguments suggest that, in contrast to the negative impacts examined in the literature, a target may emerge stronger as a result of acquisition.

\section{Hypothesis development}

\section{Competitive similarity and cost savings at the acquired firm}

According to traditional cost-efficiency theories, HAs can lead to cost savings through the achievement of economies of scale and, to a lesser extent, economies of scope. Economies of scale are achieved through asset divestitures and eliminating redundant activities and positions (Anand and Singh, 1997; Capron, 1999; Tremblay and Tremblay, 1988). Economies of scope are achieved by spreading a firm's resources and fixed costs across a broader product line (Capron, 1999; Lubatkin et al., 2001; Teece, 1980). 
It is likely that all HAs provide an opportunity to capture economies of scale and scope. However, there are likely to be more opportunities for cost savings when the acquiring and target firms are competitively similar. For example, acquiring and target firms that both place great emphasis on marketing and advertising, or both have high degrees of capital intensity, should be more likely to find overlapping skills and activities in their workforces or in their fixed assets. Thus, management will have an easier time redeploying resources across competitively similar firms, reducing operating costs and overhead expenses. Furthermore, from the seller's perspective, the target's key stakeholders may be more likely to recognize potential synergies and support the realization of those synergies when the buyer is competitively similar to the target.

Hypothesis 1: Competitive similarity will be positively related to post-acquisition cost savings at the target.

\section{Competitive similarity and revenue enhancement at the acquired firm}

Competitively dissimilar firms target different customer groups or focus on different geographic markets. Once the HA is complete, then both units (target and acquirer) should have access to a wider array of products (or models), greater marketing resources/knowledge, and different distribution networks. Similarly, each unit should be able to reach a wider array of customers. Further, as shown in Capron (1999), combining firms focusing on different geographic markets may lead to an enhanced innovation capability in the two units. All these factors should lead to opportunities for growing revenue at an increased rate.

Additionally, competitively dissimilar firms (within the same industry) typically place different degrees of emphasis on marketing, product development, etc. Barney (1988) and Harrison et al. (1991) argue that unique and inimitable synergies are more likely to be developed between firms that 
are competitively dissimilar and have different resource bases. Furthermore, Capron et al. (2001) suggest that resource asymmetries between the acquirer and target facilitate resource redeployment and subsequent acquisition performance. Thus, it is more likely that a redeployment of tacit skills and organizational knowledge will take place between the acquirer and target when they are competitively dissimilar. In doing so, the skill and resource bases of both units should be strengthened, likely enhancing growth prospects. Further, from a seller's perspective, because the synergies that can result from combining with a competitively dissimilar acquirer are primarily new growth opportunities, various stakeholders of the target will likely benefit from these synergies and therefore support the integration process.

Hypothesis 2: Competitive similarity will be negatively related to post-acquisition rates of revenue growth at the target. ${ }^{3}$

\section{Organizational similarity and the HA integration process}

While competitive similarity affects the magnitude of the potential synergies that may result from an acquisition, the degree to which these synergies are eventually realized will depend on organizational similarity, referring to the degree to which the acquired and acquiring firms share similar managerial approaches and corporate cultures (Larsson and Finkelstein, 1999; Stahl and Voigt, 2008).

Fully realizing synergies entails significant human interaction and coordination between newly-combined units. Organizational dissimilarity, driven by differences in managerial and corporate cultures, makes these interactions and coordinated activities more difficult to manage. Particularly, Larsson and Finkelstein (1999) report that a high need for integration can lead to more active resistance by employees of both the acquired and acquiring units. Organizational dissimilarity increases mistrust and misunderstanding between managers. Furthermore, studies taking a seller's 
perspective have shown that the target's managers value organizational rapport (Graebner and Eisenhardt, 2004). Thus, we expect that organizational similarity will enhance the likelihood that synergies will be realized, regardless of whether they involve cost reduction or revenue-enhancing activities.

Hypothesis 3a: Greater competitive similarity will lead to a higher likelihood of cost savings at the target when the target and acquirer are organizationally similar.

Hypothesis 3 b: Greater competitive dissimilarity (i.e. less competitive similarity) will lead to a higher likelihood of revenue growth at the target when the target and acquirer are organizationally similar.

\section{Competitive similarity and profitability improvement}

As evidenced by our first two hypotheses, prior literature suggests that competitive similarity has divergent effects on cost savings and revenue growth at the target; a high level of competitive similarity may lead to more cost savings, but there will be fewer opportunities for revenue growth. In contrast, a low level of competitive similarity may limit opportunities for achieving cost savings, but may lead to faster revenue growth. Because both cost savings and revenue growth can lead to profitability improvement, the relationship between competitive similarity and profitability improvement at the target may depend on whether the combining firms primarily seek cost savings or revenue growth. Specifically, a negative relationship between the two will likely be observed when the acquisition is mainly driven by revenue growth, whereas a positive relationship will be likely when the acquisition is driven by cost savings. Studies of acquisitions involving non-publically traded and state-owned firms show that the seller's decisions about whether to sell and to whom are affected by the target's future growth prospects (Antal-Mokos and Toth, 2007; Darskuviene, 2007; 
Graebner and Eisenhardt, 2004). Given that our research context is China, where the majority of firms are either state-owned or not publically traded, we expect that revenue growth is likely to be emphasized during the negotiation and integration process (though cost savings may still be pursued whenever possible). We therefore hypothesize that:

Hypothesis 4: Competitive similarity will be negatively related to post-acquisition profitability improvement at the target.

\section{Methodology}

Sample and data sources

The sample for this study consists of 139 HAs conducted by twenty acquirers in China's beer industry during the period 1999-2006. The beer industry has been frequently used to investigate strategic issues (Hatten et al., 1978; Houthoofd and Heene, 1997; Johnson and Thomas, 1987), providing us with a rich literature to identify key strategic characteristics in the industry. The number of acquisitions conducted by each acquirer in our data ranges from one to 32 (with an average of seven).

We performed several steps to collect acquisition information. First, we reviewed an Annual Industrial Census dataset (hereafter 'census data') provided by the National Bureau of Statistics of China (NBSC). This dataset includes annual demographic and financial information of all state-owned enterprises (SOEs) and non-SOEs operating in China with annual sales revenues of CNY5,000,000 or greater, and has been used by multiple studies (Chang and Xu, 2008; Park et al., 2006). We first identified firms that disappeared from the database or changed their names or/and ownership types, and then checked these firms' websites and media reports to determine if the changes were caused by an acquisition. Second, we reviewed the annual reports of listed companies for information on acquisitions made. Finally, we checked the websites of large unlisted breweries to 
identify any possible acquisition activities. We obtained demographic and financial information of the acquiring and acquired firm from the census data.

\section{Dependent variables}

Cost savings. We considered savings in three major costs of the target firm: (1) savings in the cost of goods sold that could be achieved via economies of scale in areas such as procurement and production; (2) savings in overhead costs that could be achieved via economies of scale in management; (3) savings in marketing expenses (i.e. expenditures related to marketing and distributing a firm's products) that could be achieved via economies of scale in marketing. These three types of costs account for 90 per cent of an average firm's sales in our sample.

We divided each of the three costs by the target's sales to take consideration of differences in firm size. We then calculated the savings in each type of costs by computing the differences between two years prior to and two years after the acquisition (e.g. savings in marketing expenses $=$ the average of the marketing expenses-to-sales-ratio in the two years prior to the acquisition - the average of marketing expenses-to-sales-ratio in the two years after the acquisition). The larger the variable, the more cost savings occurred at the target. Using a four-year time window to examine acquisition outcomes is consistent with earlier empirical studies (Bruton et al., 1994; Morosini et al., 1998; Zollo and Singh, 2004). The year in which the acquisition occurred was excluded because it was impossible to pinpoint the exact date on which the acquisition was actually finalized (Meeks and Meeks, 1981; Ramaswamy, 1997).

Revenue growth. We measured revenue growth as the percentage increase in the target's sales in the two years after the acquisition from the two years prior to the acquisition (revenue growth $=$ (average 
sales in the two years after the acquisition - average sales in the two years prior to the acquisition)/average sales in the two years prior to the acquisition).

Profitability improvement. We measured profitability improvement by calculating changes in the target's return on assets (ROA) from the two years prior to the acquisition to the two years after the acquisition. ROA has been observed as the least sensitive to the upward or downward estimation bias that can be induced by changes in leverage or bargaining power resulting from an acquisition (Meeks and Meeks, 1981).

\section{Independent variables}

Competitive similarity. Following previous studies, we operationalized competitive similarity using similarities in key strategic characteristics of the acquirer and target pre-acquisition (Capron et al., 2001; Harrison et al., 1991; Homburg and Bucerius, 2006; Ramaswamy, 1997). We identified six strategic characteristics based on studies on strategic similarity and studies on the beer industry. The first was marketing intensity. Multiple studies have identified differences in firms' emphases on marketing as an important indicator of differences in their strategies (Finkelstein and Hambrick, 1990; Ramaswamy, 1997; Swaminathan et al., 2008). Studies on the beer industry have also identified marketing expenditure as a key strategic variable (Hatten et al., 1978; Houthoofd and Heene, 1997; Johnson and Thomas, 1987). We measured marketing intensity as the ratio of marketing expenses to sales.

The second was the newness of plants. Hatten et al. (1978) identified this variable as a key strategic variable in the beer industry and found it to be positively related to breweries' performance. 
We measured this variable using the ratio of net value to gross book value of a firm's fixed assets. The third strategic characteristic was the level of a firm's current assets, such as receivables, cash, and inventory. Houthoofd and Heene (1997) noted that a firm's commitment to inventories, receivables and cash is important for a differentiation strategy. We calculated this variable using the ratio of current assets to sales.

The fourth strategic characteristic was investment intensity. Houthoofd and Heene (1997) argued that investment intensity has a positive relationship with innovation. Similarly, Johnson and Thomas (1987) suggested that capital and investment intensity capture the differentiating production or technology characteristics of the beer industry. We divided a firm's long-term investment by total assets to obtain its investment intensity. The fifth strategic characteristic was fixed-assets intensity. According to Houthoofd and Heene (1997), this variable may reflect a brewery's efforts on efficiency and search for cost advantages. We measured this variable with the ratio of a firm's fixed assets to total assets.

The last strategic characteristic was a firm's geographic market coverage. Overlap in market coverage has been repeatedly used to measure strategic similarity between combining firms (Capron, 1999; Capron et al., 2001; Homburg and Bucerius, 2006). In the beer industry, geographic coverage has also been identified as a key strategic variable (Hatten et al., 1978; Johnson and Thomas, 1987). In China, the industry is highly fragmented; a firm usually serves its local market and adjacent cities, owing to high transportation costs and local government protection (Heracleous, 2001; Slocum et al., 2006). We therefore defined a firm's market coverage based on the location of its plants.

Following the literature (Deephouse, 1999; Fuentelsaz and Gomez, 2006; Gimeno and Woo, 1996), we measured competitive similarity using a synthesized index calculated based on the above 
strategic characteristics. This approach reflects the integrative nature of strategy and increases model parsimony (Deephouse, 1999). We first calculated the Euclidean distance between the acquirer and target on these strategic variables and then normalized the distance variable to the $0-1$ range and subtracted it from one to obtain a competitive similarity measure (Gimeno and Woo, 1996). Specifically, the following formula was used:

Competitive similarity $=1-\frac{\sqrt{\sum_{j=1}^{6} \text { difference on strategic characteristic }{ }_{j}^{2}}}{\sqrt{\sum_{j=1}^{6} \text { difference on strategic characteristic }{ }_{j}^{2}}}$

$j:$ the $j^{\text {th }}$ strategic characteristics

For the first five strategic characteristics, the difference between the two firms was calculated using their respective values on each strategic variable in the two years prior to the acquisition. We standardized each variable before calculating the difference.

For difference in the acquirer and target's geographic market coverage, we created an ordinary variable based on their locations. In the census data, the location of a firm is coded with a 6-digit coding system (similar to the zip code system). The first digit represents the region in which the firm is located (the mainland of China is divided into six regions: Huabei, Dongbei, Huazhong, Huanam, Xibei, and Xinan); the first two digits together represent the province; the third and fourth the city (the third digit usually represents the city while the fourth represents a specific district in that city); and the fifth and sixth the county. The ordinary variable was coded 1 if the acquirer and target have exactly the same location code, 2 if only the first five digits of the two firms' location codes are the same, 3 if only the first four digits are the same, 4 if only the first three digits are the same, 5 if only the first 2 digits are the same, 6 if only the first digit is the same and the two firms are in 
neighboring provinces, 7 if the first digit is the same, but the two firms are not in neighboring provinces, and 8 otherwise. We also standardized this variable before adding it to the above formula for calculating competitive similarity.

Organizational similarity. Similar to competitive similarity, organizational similarity was measured using key organizational characteristics of the combining firms prior to the acquisition. Key organizational elements that have been identified affecting organizational fit between an acquirer and target include organizational culture (Chatterjee et al., 1992; Lubatkin et al., 1999), management style/administrative practices (Datta, 1991; Homburg and Bucerius, 2006; Larsson and Finkelstein, 1999), and reward and evaluation systems (Datta, 1991). These organizational elements often are formed under the influence of the cultural and institutional environments in which a firm is embedded (Lau et al., 2002; Ralston et al., 2008; Tsui et al., 2006). We therefore identified four organizational variables that may capture organizational differences based on China's context.

The first was ownership. In China, firms exist with different ownership structures that underlie differences in organizational culture as well as management systems and styles (Child, 2000; Tsui et al., 2006). In general, firms can be divided into three major categories based on their ownership, namely domestically-owned firms, firms with foreign funds, and firms with funds from Hong Kong, Macao, and Taiwan. Within each category, there are sub-categories of ownership type (for example, domestic firms can be divided into state-owned, collectively-owned, etc.). The Appendix provides a list of all ownership types and their corresponding code used by the NBSC in the annual industrial census. Multiple studies have shown that organizational culture and management styles vary across the major ownership types as well as across sub-categories within each major 
ownership type (Deshpande and Farley, 2000; Ding et al., 1997; Lau et al., 2002; Tsui et al., 2006; Wang et al., 2007).

The second organizational variable was firm age. Tsui et al. (2006) found that organizational cultural values are affected by firm age, measured as the number of years since a firm was founded. The third organizational variable was the economic development of the province where a firm is located. A contextual reality in China is that there are significant regional differences in economic development. Lau et al. (2002) found that this regional difference results in differences in employees' predisposition toward change and development culture. Provincial economic development was measured using per capita gross domestic product (GDP).

The fourth organizational variable was employee compensation, which may reflect a firm's reward and evaluation systems. Employee compensation was measured using the total wages and benefits of a firm divided by the number of employees of the firm. Information on provincial per capita GDP was obtained from various years' Statistics Year Book of China; information for other organizational variables was obtained from the census data.

Similar to measuring competitive similarity, we measured organizational similarity using a synthesized index calculated based on the above organizational characteristics. We first calculated the Euclidean distance between acquirer and target on the four organizational strategic variables; we then normalized the distance variable to the 0-1 range and subtracted it from one to obtain an organizational similarity measure.

For ownership difference, we created an ordinary variable based on the 3-digit code of ownership types listed in the Appendix. The variable equaled 1 if the two firms have exactly the same ownership code, 2 if only the first two digits of the ownership code are the same, 3 if only the first digit is the same, 4 if one of the two firms is a domestically-owned firm and the other is a firm with 
funds from Hong Kong, Macao or Taiwan, and 5 otherwise. We standardized this variable before adding it to the calculation of organizational similarity. For differences in firm age, provincial per capita GDP, and employee compensation, we standardized these variables and then calculated the differences between the two firms in the two years prior to the acquisition.

\section{Control variables}

For all models, we controlled for the target's prior-acquisition profitability and the relative size of the acquired firm with respect to the acquirer. It has been suggested that relative size is positively related to synergy potential (Seth, 1990) and realized synergies (Capron, 1999). Additionally, larger and better-performing targets may enjoy a higher relative standing in the combined company and a lower management departure after the acquisition, reducing detrimental disruptions caused by the acquisition (Cannella and Hambrick, 1993; Hambrick and Cannella, 1993; Very et al., 1997). We measured a target's pre-acquisition profitability using its industry-adjusted ROA in the two years prior to the acquisition. Relative size was measured as the ratio of the target's sales to the acquirer's sales two years prior to the acquisition.

We also controlled for each acquirer's pre-acquisition profitability, acquisition experience, and nationality (i.e. foreign versus domestic). Managers of more profitable acquirers may be more confident in their abilities and thus more likely to dominate during the integration process (Hambrick and Cannella, 1993). Acquirers' pre-acquisition profitability was measured using its industry-adjusted ROA in the two years prior to the acquisition. Acquirers with greater acquisition experience may be more capable of conducting acquisitions and thus perform better (Hambrick and Cannella, 1993; Zollo and Singh, 2004). Acquisition experience in an acquirer was measured by the number of HAs it had made in the beer industry prior to the focal acquisition. Zeng and $\mathrm{Wu}(2007)$ 
showed that compared to domestic acquirers, foreign acquirers are more likely to select strategically similar targets. Therefore, we controlled for the acquirer's nationality using a dummy variable equal to 1 if the acquirer is not originally from China and 0 otherwise.

Finally, we controlled for the year in which an acquisition occurred to take consideration of possible macro-level changes that may affect the dependent variables.

\section{Analysis and results}

Table 1 presents the descriptive statistics and correlation matrix for all variables. In order to reduce the risk of multicollinearity, we mean-censored the independent and control variables (Aiken and West, 1991). The highest variance inflation factor in the models was 1.1, indicating a low threat of multicollinearity. Because we have multiple dependent variables that very likely have related errors (i.e. integration activities may simultaneously affect costs savings, sales growth and profitability at the target), we applied seemingly unrelated regression (SUR), a statistical technique that solves a set of regression equations simultaneously and allows for error covariance among the equations (Zellner, 1962). Since there are five dependent variables in our study (savings in cost of goods sold, savings in overhead costs, savings in marketing expenses, revenue growth, and profitability improvement), five regressions were run simultaneously at each time. For each dependent variable, the control variables were included in Model 1, competitive and organizational similarity were entered in Model 2, and the interaction term between competitive and organizational similarity in Model 3 (there is no interaction term in the model where target profitability improvement is the dependent variable).

Table 2 tests the relationships between competitive similarity and the three types of cost savings. The dependent variable is savings in cost of goods sold in Panel 1, savings in overhead expenses in Panel 2, and savings in marketing expenses in Panel 3. As shown in Model 2 in Panels 1-3, competitive similarity has a negative effect on cost savings at the target. These results are inconsistent 
with Hypothesis 1's prediction of a positive relationship between competitive similarity and cost savings. We will provide possible explanations for these results in the discussion section.

Model 3 of the three panels in Table 2 tests Hypothesis 3a, which predicts that greater competitive similarity will lead to a higher likelihood of cost savings at the target when the target and acquirer are organizationally similar. The interaction term between competitive and organizational similarity has a significant and positive coefficient in all three panels. Because the main effect of competitive similarity is the opposite of our prediction, it is difficult to interpret this interaction effect by simply looking at the sign of the coefficient of the interaction term. Following Aiken and West's (1991) suggestion, we plotted the relationship between competitive similarity and the target's cost savings when organizational similarity is at a high (one standard deviation above the mean) and a low level (one standard deviation below the mean) in Figures 1-3, in order to gain a better understanding of the interaction effect.

As shown in Figure 1, savings in cost of goods sold increase with the increase of competitive similarity when organizational similarity is high, but an opposite relationship applies when organizational similarity is low. Figure 2 shows a similar pattern - a positive relationship between overhead expenses and competitive similarity when organizational similarity is high and a negative relationship when organizational similarity is low. These results are consistent with Hypothesis $3 a-$ organizational similarity facilitates the realization of cost savings resulting from competitive similarity. The patterns in Figure 3, however, do not confirm Hypothesis 3a - there is a negative relationship between savings in marketing expenses and competitive similarity regardless of the level of organizational similarity.

Table 3 reports results for the effect that competitive similarity has on the target's revenue growth. Consistent with the prediction of Hypothesis 2, there is a significantly negative relationship 
between competitive similarity and the target's sales growth. Model 3 tests Hypothesis $3 \mathrm{~b}$, which predicts that competitive dissimilarity will lead to a higher likelihood of revenue growth at the target when the acquirer and target are organizationally similar. Inconsistent with this prediction, the interaction between competitive and organizational similarity is insignificant.

Table 4 tests the effect of strategic similarity on profitability improvement at the target. Consistent with the prediction of $\mathrm{H} 4$, competitive similarity has a significant, negative relationship with the improvement of the target firm's post-acquisition ROA.

\section{Discussion and conclusions}

This study was intended to enhance our understanding of the impacts that HAs have on target firms in China's context. Drawing on cost-efficiency theories, the resource-based view of the firm, and a seller's perspective on acquisition, we examined how cost savings, revenue growth and profitability at the target are simultaneously affected by the two components of strategic similarity, namely competitive and organizational similarity. We tested our hypotheses using a unique dataset containing information about acquired firms in HAs in China's beer industry.

Our results (see Figures 1-3) show that although competitively similar targets and acquirers are able to realize minor savings in cost of goods sold and overhead expenses when they are also organizationally similar, much greater cost savings occur when both competitive and organizational dissimilarity are high. What appears to occur is that steep reductions are made in the target's spending (cost of goods sold, overhead, marketing) when target and acquirer compete differently and have different managerial practices and cultures.

One possible explanation of these findings is that many acquired firms in a transitional economy like China are state-owned or formerly-state-owned firms that lack the ability and knowledge to 
effectively compete as a market entity (Zeng et al., 2013). Significant restructuring of these firms after acquisition is often necessary to transfer them into competitive market entities (Meyer and Estrin, 2001; Meyer \& Lieb-Doczy, 2003). Being acquired by a firm that is both competitively and organizationally dissimilar may imply more opportunities for operational restructuring as well as management reform, which in turn leads to production and management efficiency at the target. This explanation is consistent with the negative relationship between the target's pre-acquisition profitability and cost savings in Table 2, which indicates that cost savings are more likely to occur in targets that performed poorly prior to acquisition.

We also found that combining competitively dissimilar firms led to more opportunities for revenue growth at the target. This result supports the stream of literature emphasizing the beneficial effects of strategic differences (Barney, 1988; Harrison et al., 1991; Larsson and Finkelstein, 1999). Furthermore, our results show that the realization of this revenue-enhancing synergy does not depend on organizational similarity between acquirer and target. This finding is consistent with the notion that the realization of revenue-based synergies involves less structural change, a low level of resource and activity consolidation, and a high level of autonomy at the target (Ambrosini et al., 2011; Stahl and Voigt, 2008; Zaheer et al., 2013). All these integration characteristics reduce the likelihood of problems that might arise from organizational differences.

Finally, consistent with our expectation, targets acquired by competitively dissimilar acquirers are found to experience greater post-acquisition profitability improvement. This result may reflect the contextual feature that the target's growth prospects are a key determinant of the seller's decisions concerning the acquisition (e.g. whether to sell and to whom) in emerging markets (Antal-Mokos and Toth, 2007; Darskuviene, 2007). This contextual feature may lead to an emphasis on achieving revenue growth through combining with competitively dissimilar firms. 
Our study contributes to the literature on Asian business as well as research on acquisitions. First, although acquisitions in China have been growing significantly since the 1990s, academic investigation of these acquisitions is scarce. The few studies examining acquisitions in China focus on either firms' acquiring/selling strategies (Xu et al, 2010; Zeng et al., 2013; Zou, 2008) or the stock market's reactions to acquisition announcements (Gaur et al., 2013). As a result, little is known about acquisition outcomes, and in particular outcomes at the target. Our study therefore enhances the literature by comprehensively examining how a target firm may be affected by strategic similarity, a factor that has been identified as the most likely predictor of HA outcomes.

Second, our focus on the target's post-acquisition operations advances the acquisition literature. Although the acquired firm usually becomes a part of the acquiring firm after the acquisition, many of its stakeholders continue interacting with it. Understanding acquisition outcomes from the target's perspective will not only help the acquirer to better intact with these stakeholders, but could also help the target's stakeholders to make better-informed decisions. Particularly in a context like China, where the seller can play an active role in the acquiring and integration process, an understanding of how the target will be impacted by the acquisition may not only facilitate the occurrence of an acquisition, but could also reduce the acquisition price and integration costs (Graebner, 2004; Graebner and Eisenhardt, 2004).

Third, our study also contributes to the acquisition literature by examining cost savings and revenue growth at the target simultaneously. This approach allows us to integrate efficiency theories and the resource-based view of the firm and helps address the inconsistent views on whether combining strategically dissimilar or similar firms is more beneficial (Barney, 1988; Chatterjee, 1986; Harrison, et al., 1991; Ramaswamy, 1997). Finally, our study enhances our understanding of the interaction between competitive and organizational similarity, an area that remains 
under-explored (Stahl and Voigt, 2008). Our findings of the significant interaction effect between competitive and organizational similarity on cost savings and the insignificant effect between the two on revenue growth indicate that a contingency model is necessary when examining the relationship between strategic similarity and acquisition outcomes.

Our study has important implications for managers. Our findings show that strategic dissimilarity is beneficial to the target in China's context, not only by leading to revenue-enhancing synergies, but also by resulting in more cost savings. Additionally, in contrast to the well-acknowledged importance of organizational similarity in post-acquisition integration, it seems that in a transition economy like China, organizational dissimilarity facilitates the restructuring of the target, which in turn leads to cost savings. Therefore, managers should pay special attention to the potential benefits of strategic differences when evaluating acquisition targets and factors affecting acquisition outcomes.

Our study is not free of limitations. First, although our measures of competitive and organizational similarity were based on key strategic and organizational variables identified in the literature, they may not be able to thoroughly capture these concepts given the secondary nature of our data. Future studies may use survey or interview methods to obtain a more direct measure of these concepts. Second, data availability required that we examine changes in the performance of the target firm for two years following the year of its acquisition. It may be that some changes, particularly those associated with cost reductions, may take longer than two years to be fully realized. Thus, our two-year window may provide only a partially-complete picture of this event. Third, we focused on HAs only in China's beer industry. Although this approach allowed us to avoid complexities that could be caused by differences in industries if HAs in multiple industries were used, the 
generalizability of our results needs to be confirmed by future studies using data from different industries.

\section{Notes}

1. Ravenscraft and Scherer $(1987,1989)$ investigated the post-acquisition performance of targets, but did not focus exclusively on horizontal acquisitions.

2. The beneficial outcomes of HA (cost savings, revenue growth, etc.) can occur at either the acquiring or acquired firm (or both). However, our study purposely focuses on effects of the HA at the acquired firm. This focus is not meant to imply that most or all HA effects occur at the target firm. 3. We have used the term competitive similarity, as opposed to competitive dissimilarity, in $\mathrm{H} 2$ to keep the wording consistent across hypotheses. Alternatively, we could have stated this hypothesis such that competitive dissimilarity will be positively related to post-acquisition revenue growth at the target.

\section{References}

Ahuja, G. and Katila, R. (2001) Technological acquisitions and the innovation performance of acquiring firms: A longitudinal study. Strategic Management Journal 22: 197-219.

Aiken, L.S. and West, S.G. (1991) Multiple regression: Testing and interpreting interactions. Newbury Park: Sage.

Altunbas, Y. and Marques, D. (2008) Mergers and acquisitions and bank performance in Europe: The role of strategic similarities. Journal of Economics \& Business 60: 204-222. 
Ambrosini, V., Bowman, C. and Schoenberg, R. (2011) Should acquiring firms pursue more than one value creation strategy? An empirical test of acquisition performance. British Journal of Management 22: 173-185.

Anand, J., and Singh, H. (1997) Asset redeployment, acquisitions and corporate strategy in declining industries. Strategic Management Journal 18: 99-118.

Antal-Mokos, Z. and Toth, K. (2007) 'The emergence of the Central European MNE: MOL'. In K.E. Meyer and S. Estrin (eds.) Acquisition Strategies in European Emerging Markets. Basingstoke: PalgraveMacmillan, pp.190-202.

Barney, J.B. (1988) Returns to bidding firms in mergers and acquisitions: Reconsidering the relatedness hypothesis. Strategic Management Journal 9: 71-78.

Barney, J.B. (2002) Gaining and sustaining competitive advantage. Upper Saddle River: Prentice Hall.

Bruton, G.D., Oviatt, B.M. and White, M.A. (1994) Performance of acquisitions of distressed firms. Academy of Management Journal 37: 972-989.

Cannella, A.A. and Hambrick, D.C. (1993) Effects of executive departures on the performance of acquired firms. Strategic Management Journal 14: 137-152.

Capron, L. (1999) The long-term performance of horizontal acquisitions. Strategic Management Journal 20: 987-1018.

Capron, L., Dussauge, P. and Mitchell, W. (1998) Resource redeployment following horizontal acquisitions in Europe and North America, 1988-1992. Strategic Management Journal 19: 631-661.

Capron, L., Mitchell, W. and Swaminathan, A. (2001) Asset divestiture following horizontal acquisitions: A dynamic view. Strategic Management Journal 22: 817-844. 
Cartwright, S. and Schoenberg, R. (2006) Thirty years of mergers and acquisitions research: Recent advances and future opportunities. British Journal of Management 17: S1-S5.

Chang, S.J. and Xu, D. (2008) Spillovers and competition among foreign and local firms in China. Strategic Management Journal 29: 495-518.

Chatterjee, S. (1986) Types of synergy and economic value: The impact of acquisitions on merging and rival firms. Strategic Management Journal 7: 119-139.

Chatterjee, S., Lubatkin, M.H., Schweiger, D.M. and Weber, Y. (1992) Cultural differences and shareholder value in related mergers: Linking equity and human capital. Strategic Management Journal 13: 319-334.

Chen, Y.Y. and Young, M.N. (2010) Cross-border mergers and acquisitions by Chinese listed companies: A principal-principal perspective, Asia Pacific Journal of Management 27: 523-539.

Child, J. (2000) Management and organizations in China: Key trends and issues. In: J.T. Li, S.A. Tsui and E. Weldon (eds.) Management and Organizations in the Chinese Context. London: Palgrave Macmillan, pp.33-62.

Darskuviene, V. (2007) Early entry and aggressive growth: Kraft foods Lietuva. In: K.E. Meyer and S. Estrin (eds.) Acquisition Strategies in European Emerging Markets. Basingstoke: PalgraveMacmillan, pp.232-241.

Datta, D.K. (1991) 'Organizational fit and acquisition performance: Effects of post-acquisition integration'. Strategic Management Journal 12: 281-297.

Deephouse, D.L. (1999) To be different, or to be the same? It's a question (and theory) of strategic balance. Strategic Management Journal 20: 147-166. 
Deshpande, R. and Farley, J.U. (2000) Market-focused organizational transformation in China. Journal of Global Marketing 14: 7-35.

Ding, D., Fields, D. and Akhtar, S. (1997) An empirical study of human resource management policies and practices in foreign-invested enterprises in China: the case of Shenzhen Special Economic Zone. International Journal of Human Resource Management 8: 595-613.

Dranove, D. and Shanley, M. (1995) Cost reductions or reputation enhancement as motives for mergers: The logic of multihospital systems. Strategic Management Journal 16: 55-74.

Eckbo, B.E. (1983) Horizontal mergers, collusion and stockholder wealth. Journal of Financial Economics 11: 241-273.

Fee, C.E. and Thomas, S. (2004) Sources of gains in horizontal mergers: evidence from customer, supplier and rival firms. Journal of Financial Economics 74: 423-460.

Finkelstein, S. and Hambrick, D.C. (1990) Top-management-team tenure and organizational outcomes: The moderating role of managerial discretion. Administrative Science Quarterly 35: 484-503.

Fuentelsaz, L. and Gomez, J. (2006) Multipoint competition, strategic similarity and entry into geographic markets. Strategic Management Journal 27: 477-499.

Gaur, A.S., Malhotra, S. and Zhu, P. (2013) Acquisition announcements and stock market valuations of acquiring firms rivals: A test of the growth probability hypothesis in China. Strategic Management Journal 34(2): 215-232.

Gimeno, J. and Woo, C.Y. (1996) Hypercompetition in a multimarket environment: The role of strategic similarity and multimarket contact in competitive de-escalation. Organization Science 7: $322-341$. 
Graebner, M.E. (2004) Momentum and serendipity: How acquired leaders create value in the integration of technology firms. Strategic Management Journal 25: 751-777.

Graebner, M.E. and Eisenhardt, K.M. (2004) The sellers' side of the story: Acquisition as courtship and governance as syndicate in entrepreneurial firms. Administrative Science Quarterly 49: 366-403.

Haleblian, J., Devers, C.E., McNamara, G., Carpenter, M.A. and Davison, R.B. (2009) Taking stock of what we know about mergers and acquisitions: A review and research agenda. Journal of Management 35: 469-502.

Hambrick, D.C. and Cannella, A.A. (1993) Relative standing: A framework for understanding departures of acquired executives. Academy of Management Journal 36: 733-762.

Harrison, J.S., Hitt, M.A., Hoskisson, R.E. and Ireland, R.D. (1991) Synergies and post-acquisition performance: Differences versus similarities in resource allocations. Journal of Management 17: $173-190$.

Hatten, K.J., Schendel, D.E. and Cooper, A.C. (1978) A strategic model of the U.S. brewing industry: 1952-1971. Academy of Management Journal 21: 592-610.

Heracleous, L. (2001) When local beat global: the Chinese beer industry. Business Strategy Review 12: $37-45$.

Hitt, M., Harrison, J., Ireland, R.D. and Best, A. (1998) Attributes of successful and unsuccessful acquisitions of US firms. British Journal of Management 9: 91-114.

Homburg, C. and Bucerius, M. (2006) Is speed of integration really a success factor of mergers and acquisitions? An analysis of the role of internal and external relatedness. Strategic Management Journal 27: 347-367. 
Houthoofd, M.e. and Heene, A. (1997) Strategic groups as subsets of strategic scope groups in the Belgian brewing industry. Strategic Management Journal 18: 653-666.

Jemison, D.B. and Sitkin, S.B. (1986) Corporate acquisitions: A process perspective. Academy of Management Review 11: 145-163.

Johnson, G. and Thomas, H. (1987) The industry context of strategy, structure and performance: The U.K. brewing industry. Strategic Management Journal 8: 343-361.

Kusewitt, J.B. (1985) An exploratory study of strategic acquisition factors relating to performance. Strategic Management Journal 6: 151-169.

Larsson, R. and Finkelstein, S. (1999) Integrating strategic, organizational and human resource perspectives on mergers and acquisitions: A case survey of synergy realization. Organization Science 10: 1-26.

Lau, C-M., Tse, D.K. and Zhou, N. (2002) Institutional forces and organizational culture in China: Effects on change schemas, firm commitment and job satisfaction'. Journal of International Business Studies 33: 533-550.

Lubatkin, M., Schulze, W.S., Mainkar, A. and Cotterill, R.W. (2001) Ecological investigation of firm effects in horizontal mergers. Strategic Management Journal 22: 335-357.

Lubatkin, M., Schweiger, D. and Weber, Y. (1999) Top management turnover in related M\&As: An additional test of the theory of relative standing. Journal of Management 25: 55-73.

Meeks, G. and Meeks, J.G. (1981) Profitability measures as indicators of post-merger efficiency. Journal of Industrial Economics 29: 335-344.

Meyer, K.E. (2002) Management challenges in privatization acquisitions in transition economies. Journal of World Business 37: 266-276. 
Meyer, K.E. and Estrin, S. (2001) Brownfield entry in emerging markets. Journal of International Business Studies 32(3): 575-584.

Meyer, K.E. and Lieb-Doczy, E. (2003) Post-acquisition restructuring as evolutionary process. Journal of Management Studies 40(2): 459-482.

Morosini, P., Shane, S. and Singh, H. (1998) National cultural distance and cross-border acquisition performance'. Journal of International Business Studies 29: 137-158.

Papadakis, V.M. and Thanos, I.C. (2010) Measuring the performance of acquisitions: An empirical investigation using multiple criteria. British Journal of Management 21: 859-873.

Park, S.H., Li, S. and Tse, D.K. (2006) Market liberalization and firm performance during Chinas economic transition. Journal of International Business Studies 37: 127-147.

Prahalad, C.K. and Bettis, R.A. (1986) The dominant logic: A new linkage between diversity and performance. Strategic Management Journal 7: 485-501.

Ralston, D.A., Holt, D.H., Terpstra, R.H. and Yu, K-C. (2008) The impact of national culture and economic ideology on managerial work values: A study of the United States, Russia, Japan and China. Journal of International Business Studies 39: 8-26.

Ramaswamy, K. (1997) The performance impact of strategic similarity in horizontal mergers:

Evidence from the U.S. banking industry. Academy of Management Journal 40: 697-715.

Ravenscraft, D.J. and Scherer, F.M. (1987) Life after takeover. Journal of Industrial Economics 36(2): 147-156.

Ravenscraft, D.J. and Scherer, F.M. (1989) The profitability of mergers. International Journal of Industrial Organization. 7(1): 101-116.

Saxton, T. and Dollinger, M. (2004) Target reputation and appropriability: Picking and deploying resources in acquisitions. Journal of Management 30: 123-147. 
Schoenberg, R. (2006) Measuring the performance of corporate acquisitions: An empirical comparison of alternative metrics. British Journal of Management 17: 361-370.

Seth, A. (1990) Sources of value creation in acquisitions: An empirical investigation. Strategic Management Journal 11: 431-446.

Shelton, L.M. (1988) Strategic business fits and corporate acquisition: Empirical evidence. Strategic Management Journal 9: 279-287.

Sheng, H. (Ed.) (1999) Cases of Chinese Enterprise Mergers and Acquisitions. Beijing: China Light Industry Press.

Slocum, J.W., Conder, W., Corradini, E., Foster, R.O.Y., Frazer, R., Lei, D., McGuire, M., Ross, J. and Scott, S. (2006) Fermentation in the China beer industry. Organizational Dynamics 35: $32-48$.

Stahl, G.K. and Voigt, A. (2008) Do cultural differences matter in mergers and acquisitions? A tentative model and examination. Organization Science 19: 160-176.

Swaminathan, V., Murshed, F. and Hulland, J. (2008) Value creation following merger and acquisition announcements: The role of strategic emphasis alignment. Journal of Marketing Research 45: 33-47.

Teece, D.J. (1980) Economies of scope and the scope of the enterprise. Journal of Economic Behavior and Organization 1: 223-247.

Teece, D.J. (1982) Towards an economic theory of the multiproduct firm. Journal of Economic Behavior and Organization 3: 39-63.

Tremblay, V.J. and Tremblay, C.H. (1988) The determinants of horizontal acquisitions: Evidence from the US brewing industry. Journal of Industrial Economics 37: 21-45. 
Tsui, A.S., Hui, W. and Xin, K.R. (2006) Organizational culture in China: An analysis of culture dimensions and culture types Management \& Organization Review 2: 345-376.

Uhlenbruck, K. and De Castro, J. (1998) Privatization from the acquirers perspective: a mergers and acquisitions based framework. Journal of Management Studies 35: 619-640.

Uhlenbruck, K. and De Castro, J.O. (2000) Foreign acquisitions in Central and Eastern Europe: Outcomes of privatization in transitional economies. Academy of Management Journal 43: $381-402$.

UNCTAD (2012) World investment report. Geneva: UNCTAD.

Very, P., Lubatkin, C., Calori, P. and Veiga, J. (1997) Relative standing and the performance of recently acquired European firms. Strategic Management Journal 18: 593-614.

Walsh, J.P. and Ellwood, J.W. (1991) Mergers, acquisitions and the pruning of managerial deadwood. Strategic Management Journal 12: 201-217.

Walter, G.A. and Barney, J.B. (1990) Management objectives in mergers and acquisitions. Strategic Management Journal 11: 79-86.

Wang, X., Yang, B. and McLean, G.N. (2007) Influence of demographic factors and ownership type upon organizational learning culture in Chinese enterprises. International Journal of Training \& Development 11: 154-165.

Xu, D., Zhou, C. and Phan, P.H. (2010) A real options perspective on sequential acquisitions in China. Journal of International Business Studies 41: 166-74.

Zaheer, A., Castaner, X. and Souder, D. (2013) Synergy sources, target autonomy and integration in acquisitions. Journal of Management 39: 604-632.

Zellner, A. (1962) An efficient method of estimating seemingly unrelated regression and tests for aggregation bias. Journal of the American Statistical Association 57: 348-368. 
Zeng, Y., Douglas, T.J. and Wu, C. (2013) The seller's perspective on determinants of acquisition likelihood: Insights from Chinas beer industry. Journal of Management Studies 50: 673-698.

Zeng, Y. and Wu, C. (2007) An institutional view on target selections in horizontal acquisitions in transition economies: Evidence from Chinese beer industry. Proceedings of the Academy of International Business Annual Meeting; 25-28 June, 2007, Indianapolis, IN. Academy of International Business.

Zollo, M. and Singh, H. (2004) Deliberate learning in corporate acquisitions: post-acquisition strategies and integration capability in U.S. bank mergers. Strategic Management Journal 25: $1233-1256$.

Zou, H. (2008) Cross-border mergers and acquisitions in China: An industry panel study, 1991-2005. Asia Pacific Business Review 14(4): 491-512. 
Figure 1: The relationship between competitive similarity and savings in cost of goods sold at high and low levels of organizational similarity

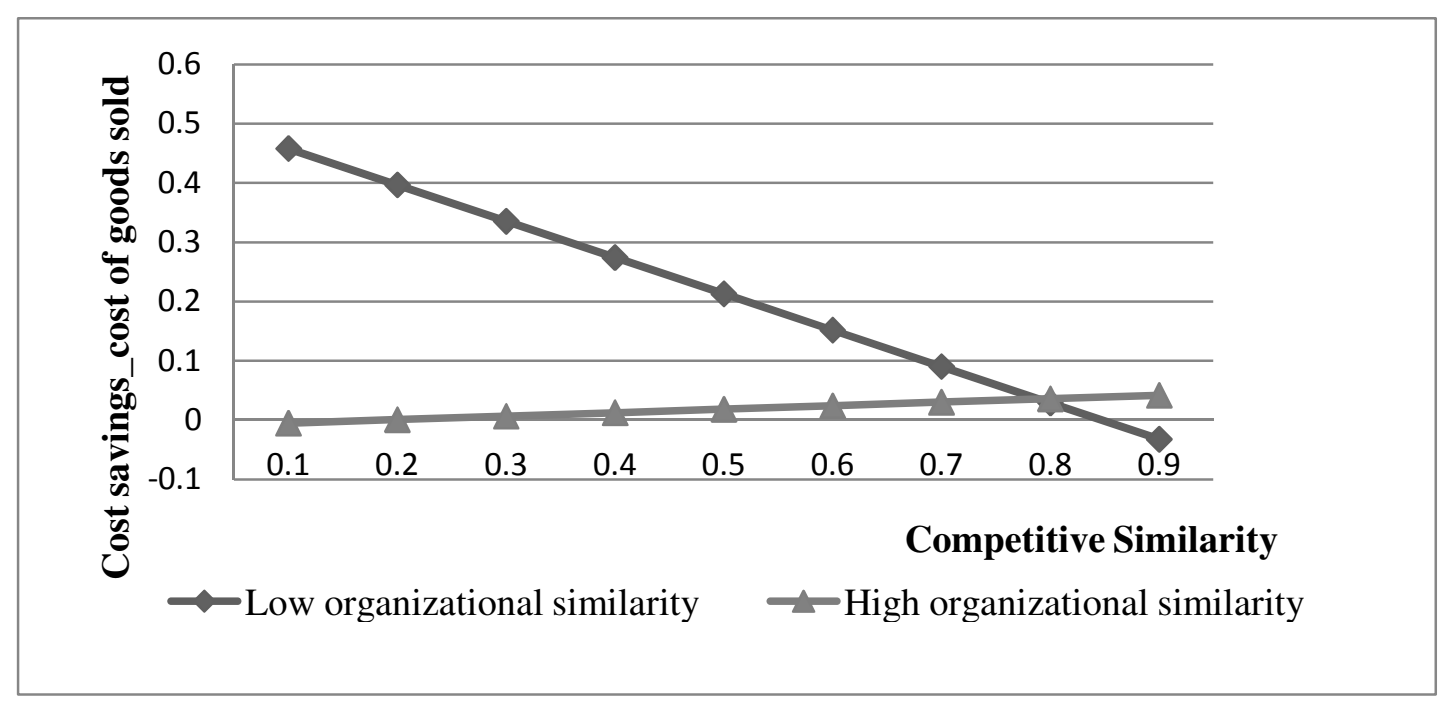

Figure 2: The relationship between competitive similarity and savings in overhead expenses at high and low levels of organizational similarity

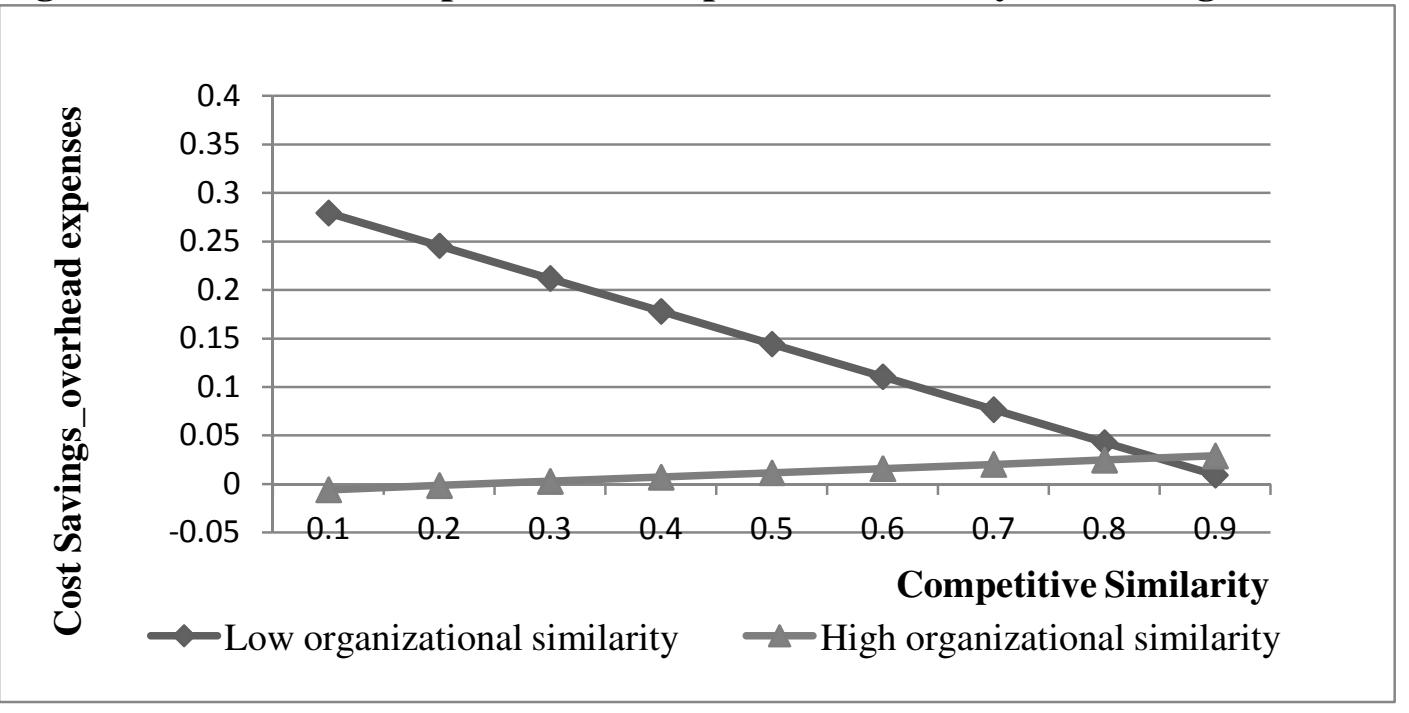

Page 36 of 46 
Figure 3: The relationship between competitive similarity and savings in marketing expenses at high and low levels of organizational similarity

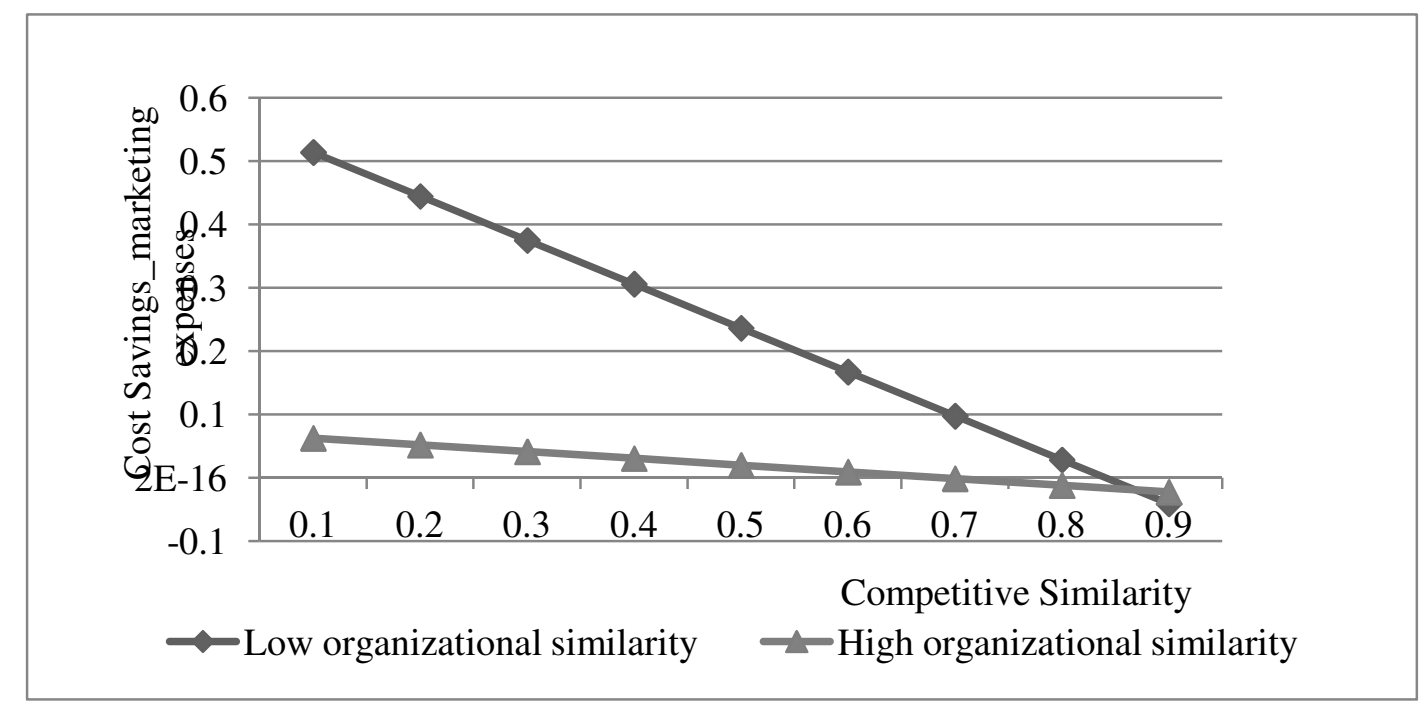


Table 1: Descriptive statistics and correlation matrix.

\begin{tabular}{|c|c|c|c|c|c|c|c|c|c|c|c|c|}
\hline & 1 & 2 & 3 & 4 & 5 & 6 & 7 & 8 & 9 & 10 & 11 & 12 \\
\hline $\begin{array}{l}1 \text { Savings in } \\
\text { cost of goods } \\
\text { sold }\end{array}$ & & & & & & & & & & & & \\
\hline $\begin{array}{l}2 \text { Savings in } \\
\text { overhead } \\
\text { expenses }\end{array}$ & $0.222 *$ & & & & & & & & & & & \\
\hline $\begin{array}{l}3 \text { Savings in } \\
\text { marketing } \\
\text { expenses }\end{array}$ & 0.019 & $0.42 *$ & & & & & & & & & & \\
\hline $\begin{array}{l}4 \text { Revenue } \\
\text { growth }\end{array}$ & $0.153^{*}$ & $0.452 *$ & 0.084 & & & & & & & & & \\
\hline $\begin{array}{l}5 \\
\text { Profitability } \\
\text { improvement }\end{array}$ & $0.442 *$ & $0.475^{*}$ & $0.384 *$ & 0.131 & & & & & & & & \\
\hline $\begin{array}{l}6 \\
\text { Competitive } \\
\text { similarity }\end{array}$ & $-0.182^{*}$ & -0.097 & -0.147 & -0.121 & -0.148 & & & & & & & \\
\hline $\begin{array}{l}7 \\
\text { organizationa } \\
1 \text { similarity }\end{array}$ & 0.03 & $-0.232 *$ & -0.159 & -0.155 & -0.013 & 0.019 & & & & & & \\
\hline $\begin{array}{l}8 \text { target } \\
\text { relative size }\end{array}$ & 0.039 & -0.024 & -0.039 & -0.003 & 0.014 & 0.112 & 0.126 & & & & & \\
\hline $\begin{array}{l}9 \text { target } \\
\text { pre-acquisitio } \\
\text { n ROA }\end{array}$ & $-0.153 *$ & $-0.283^{*}$ & $-0.337^{*}$ & -0.06 & $-0.408 *$ & -0.017 & $0.158^{*}$ & 0.028 & & & & \\
\hline $\begin{array}{l}\text { 10. acquirer } \\
\text { pre-acquisitio }\end{array}$ & 0.06 & -0.033 & -0.065 & -0.014 & -0.007 & $-0.307 *$ & -0.127 & 0.014 & 0.009 & & & \\
\hline
\end{tabular}




\begin{tabular}{|c|c|c|c|c|c|c|c|c|c|c|c|c|}
\hline $\begin{array}{l}\text { n ROA } \\
11 \text { Acquirer's }\end{array}$ & -0.095 & 0.172 & 0.079 & 0.133 & -0.026 & 0.244 & -0.271 & -0.148 & -0.05 & $-0.192 *$ & & \\
\hline $\begin{array}{l}12 \text { Foreign } \\
\text { acquirer }\end{array}$ & -0.119 & -0.047 & -0.026 & -0.109 & -0.018 & 0.207 & 0.459 & 0.145 & 0.11 & $-0.292^{*}$ & $0.154^{*}$ & \\
\hline Mean & 0.024 & 0.016 & -0.011 & 0.985 & 0.001 & 0.802 & 0.786 & 1.764 & -0.007 & 0.023 & 1.468 & 0.369 \\
\hline S.D. & 0.119 & 0.1 & 0.132 & 3.897 & 0.123 & 0.092 & 0.119 & 16.141 & 0.107 & 0.054 & 1.5 & 0.484 \\
\hline
\end{tabular}


Table 2: Strategic similarity and cost savings at the target. 


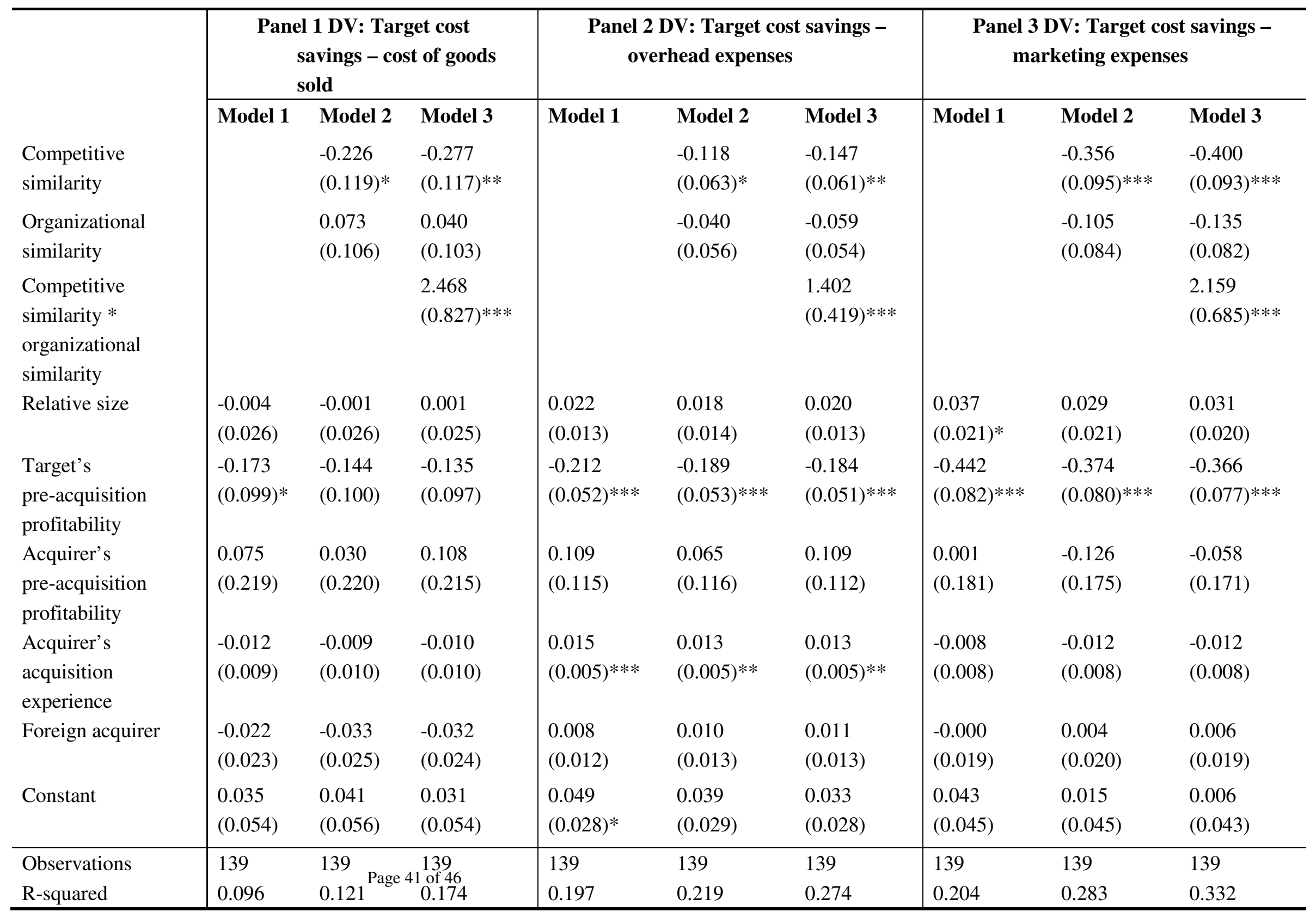


$* * * \mathrm{p}<0.01 ; * * \mathrm{p}<0.05 ; * \mathrm{p}<0$; standard errors in parentheses; year dummies included but not shown. 
Table 3: Strategic similarity and revenue growth at the target.

\begin{tabular}{|c|c|c|c|}
\hline & Model 1 & Model 2 & Model 3 \\
\hline $\begin{array}{l}\text { Competitive } \\
\text { similarity }\end{array}$ & & $\begin{array}{l}-5.923 \\
(2.460)^{* *}\end{array}$ & $\begin{array}{l}-6.471 \\
(2.473) * * *\end{array}$ \\
\hline $\begin{array}{l}\text { Organizational } \\
\text { similarity }\end{array}$ & & $\begin{array}{l}-1.724 \\
(2.177)\end{array}$ & $\begin{array}{l}-2.082 \\
(2.176)\end{array}$ \\
\hline $\begin{array}{l}\text { Competitive } \\
\text { similarity } * \\
\text { organizational } \\
\text { similarity }\end{array}$ & & & $\begin{array}{l}26.326 \\
(18.889)\end{array}$ \\
\hline Relative size & $\begin{array}{l}-0.316 \\
(0.533)\end{array}$ & $\begin{array}{l}-0.462 \\
(0.536)\end{array}$ & $\begin{array}{l}-0.437 \\
(0.532)\end{array}$ \\
\hline $\begin{array}{l}\text { Pre-acquisition } \\
\text { target profitability }\end{array}$ & $\begin{array}{l}-1.313 \\
(2.062)\end{array}$ & $\begin{array}{l}-0.192 \\
(2.066)\end{array}$ & $\begin{array}{l}-0.091 \\
(2.051)\end{array}$ \\
\hline $\begin{array}{l}\text { Acquirer's } \\
\text { pre-acquisition } \\
\text { profitability }\end{array}$ & $\begin{array}{l}-2.519 \\
(4.547)\end{array}$ & $\begin{array}{l}-4.630 \\
(4.534)\end{array}$ & $\begin{array}{l}-3.806 \\
(4.539)\end{array}$ \\
\hline $\begin{array}{l}\text { Acquirer's } \\
\text { acquisition } \\
\text { experience }\end{array}$ & $\begin{array}{l}0.074 \\
(0.195)\end{array}$ & $\begin{array}{l}0.004 \\
(0.209)\end{array}$ & $\begin{array}{l}-0.001 \\
(0.208)\end{array}$ \\
\hline Foreign acquirer & $\begin{array}{l}-0.474 \\
(0.483)\end{array}$ & $\begin{array}{l}-0.407 \\
(0.520)\end{array}$ & $\begin{array}{l}-0.388 \\
(0.516)\end{array}$ \\
\hline Constant & $\begin{array}{l}-0.234 \\
(1.117)\end{array}$ & $\begin{array}{l}-0.701 \\
(1.155)\end{array}$ & $\begin{array}{l}-0.810 \\
(1.149)\end{array}$ \\
\hline Observations & 139 & 139 & 139 \\
\hline R-squared & 0.104 & 0.143 & 0.156 \\
\hline
\end{tabular}

$* * * \mathrm{p}<0.01 ; * * \mathrm{p}<0.05 ; * \mathrm{p}<0.1$; standard errors in parentheses; year dummies included but not shown. 
Table 4: Strategic similarity and profitability improvement at the target.

\begin{tabular}{l|cc}
\hline & Model 1 & Model 2 \\
\hline Competitive & & -0.229 \\
similarity & & $(0.130)^{*}$ \\
Organizational & & 0.014 \\
similarity & & $(0.115)$ \\
Relative size & -0.020 & -0.021 \\
& $(0.028)$ & $(0.028)$ \\
Pre-acquisition & -0.441 & -0.405 \\
target & $(0.108)^{* * *}$ & $(0.109)^{* * *}$ \\
profitability & & \\
Acquirer's & 0.026 & -0.035 \\
pre-acquisition & $(0.238)$ & $(0.240)$ \\
profitability & & \\
Acquirer's & -0.005 & -0.005 \\
acquisition & $(0.010)$ & $(0.011)$ \\
experience & & \\
Foreign acquirer & 0.019 & 0.013 \\
& $(0.025)$ & $(0.028)$ \\
Constant & -0.043 & -0.048 \\
& $(0.058)$ & $(0.061)$ \\
Observations & 139 & 139 \\
R-squared & 0.161 & 0.180 \\
\hline$* * * p<0.01 ; * * \mathrm{p}<0.05 ; * 0.1 ;$ standard errors in parentheses; year \\
dummies included but not shown.
\end{tabular}


Appendix: Ownership types and codes of firms in China.

\begin{tabular}{|c|c|}
\hline Code & Ownership of Registration \\
\hline & Domestic enterprises \\
\hline 110 & State-owned enterprises (SOEs) (Guoyou qiye) \\
\hline 120 & Collectively-owned enterprises (COEs) (Qiti qiye) \\
\hline 130 & Joint-stock cooperative enterprises (Gufen hezuo qiye) \\
\hline 140 & Domestic joint ventures (Lianying qiye) \\
\hline 141 & Joint ventures between SOEs(Guoyou lianying qiye) \\
\hline 142 & Joint ventures between COEs (Jiti lianying qiye) \\
\hline 143 & Joint ventures between SOEs and COEs (Guoyou and jiti lianying qiye) \\
\hline 149 & Other domestic joint ventures (Qita lianying qiye) \\
\hline 150 & Limited-liability enterprises (LLEs) (Youxian ziren gongsi) \\
\hline 151 & State-owned LLEs (Guoyou duzi gongsi) \\
\hline 159 & Other LLEs \\
\hline 160 & Share-holding enterprises (SHEs) (Guofen youxian gongsi) \\
\hline 170 & Privately-owned enterprises (POEs) (Siyou qiye) \\
\hline 171 & Wholly privately-owned enterprises (Siyou duzi qiye) \\
\hline 172 & Private cooperative enterprises(Siying hehuo qiye) \\
\hline 173 & Privately-owned LLEs (Siying youxian zeren gongsi) \\
\hline 174 & Privately-owned SHEs (Siying youxian zeren gongsi) \\
\hline \multirow[t]{2}{*}{190} & Other types of enterprises \\
\hline & $\begin{array}{l}\text { Enterprises with funds from Hong Kong, Macao, and Taiwan } \\
\text { (HMTEs) }\end{array}$ \\
\hline 210 & HMTEs in joint-venture format (Gang, Ao, Tai hezi jingying qiye) \\
\hline 220 & HMTEs in cooperative format (Gang, Ao, Tai hezuo jingying qiye) \\
\hline 230 & Wholly-owned HMTEs (Gang, Ao, Tai duzi jingying qiye) \\
\hline \multirow[t]{2}{*}{240} & Shareholding HMTEs (Gang, Ao, Tai touzi gufen youxian gongsi) \\
\hline & Foreign invested enterprises (FIEs) \\
\hline 310 & Sino-foreign joint ventures (Zhongwai hezi jingying qiye) \\
\hline 320 & Sino-foreign cooperative enterprises (Zhongwai hezuo jingying qiye) \\
\hline 330 & Wholly-owned FIEs (Waizi qiye) \\
\hline 340 & Foreign-invested SHEs (Waishang touzi youxian gongsi) \\
\hline
\end{tabular}

Source: National Bureau of Statistics of China 


\section{Author profiles}

Dr. Yuping Zeng is an Assistant Professor at the School of Business, Southern Illinois University Edwardsville. She received her Ph.D. in Strategic Management and International Business from Peking University, China, and did her post-doctoral research at the Ohio State University. Her research interests include mergers and acquisitions, foreign direct investment, and institutional transitions. She has published articles in the Journal of International Business Studies, Journal of Management Studies, Management International Review, and several other English and Chinese journals.

Dr. Tim Schoenecker is an Associate Professor at the School of Business, Southern Illinois University Edwardsville (SIUE). He earned his Ph.D. in Strategic Management from Purdue University. At SIUE, his primary teaching assignments are in the areas of strategy and entrepreneurship. His research interests are primarily in the areas of corporate governance and top management teams. He has published in various journals, such as Strategic Management Journal, IEEE Transactions on Engineering Management, Organization Science, and Entrepreneurship: Theory and Practice. 